\title{
Acidentes típicos do trabalho rural: um estudo a partir dos registros do hospital universitário de Santa Maria, Rs, Brasil
}

Typical rural work accidents: a study of records from the University Hospital Santa Maria, RS, Brazil

\author{
Laila Mayara Drebes', Cibele Bolzan Scherer ${ }^{2}$, Jana Rossato Gonçalves ${ }^{3}$, Andrea Cristina Dörr ${ }^{4}$ \\ 1,2,3 Mestrandas no Programa de Pós-Graduação em Extensão Rural (PPGExR) da Universidade Federal de Santa Maria (UFSM),RS, Brasil. \\ ${ }^{4}$ Doutora em Economia, da Universidade Federal de Santa Maria (UFSM), RS, Brasil.
}

\begin{abstract}
Resumo
O trabalho rural é considerado um dos mais vulneráveis à ocorrência de acidentes, tendo em vista a quantidade e diversidade de riscos ocupacionais envolvidos. Apesar da importância do tema, é limitada a literatura científica dedicada a sua análise. Assim, o presente estudo teve por objetivo traçar o perfil dos trabalhadores rurais acidentados e caracterizar os acidentes. Para isso, foi conduzida uma pesquisa documental utilizando os registros de problemas de saúde do Hospital Universitário de Santa Maria (HUSM). A amostra de 38 registros foi composta por critérios não probabilísticos e os dados coletados foram analisados quantitativamente através do software Statistical Package for the Social Sciences (SPSS). O perfil traçado para o trabalhador rural acidentado é caracterizado por homens brancos e adultos, com baixo nível de escolaridade, trabalhadores autônomos, experientes e residentes no rural. Os acidentes rurais típicos são caracterizados pela variabilidade espacial (ocorrência em diversos municípios) e pela concentração temporal no período de entressafra. Ocasionados por riscos ocupacionais biológicos, ergonômicos e mecânicos, são provocados principalmente por quedas e afetam, sobretudo, membros inferiores e tórax e membros superiores, levando a incapacidade temporária do trabalhador rural. A magnitude desse problema social aponta para a necessidade de intervenção da Extensão Rural e realização de pesquisas mais específicas.
\end{abstract}

Palavras-chaves: Riscos ocupacionais; Atividades agropecuárias; Trabalhador rural; Perfil e Extensão Rural.

\begin{abstract}
The rural work is considered one of the most vulnerable to accidents, having in view the quantity and diversity of occupational risks involved. Despite the importance of the issue, is limited to scientific literature dedicated to its analysis. The aim of the present study was to delineate the profile of rural workers accidented and characterize the accidents. For this reason, a survey was conducted using the documentary records of health problems of the University Hospital Santa Maria (UFSM). The sample with 38 records was composed of non-probabilistic criteria and the collected data were analyzed quantitatively using the software Statistical Package for the Social Sciences (SPSS). The profile trace to worker injured rural is characterized by white men and adults, with a low level of schooling, autonomous, experienced workers and residents in rural. The typical rural accidents are characterized by spatial variability (different municipalities) and by temporal concentration during the period of harvest. Caused by occupational hazards biological, ergonomic and mechanics, are mainly caused by falls and affect, in particular, lower limbs and chest and upper limbs, leading to temporary inability of rural workers. The magnitude of this social problem points to the need for intervention by the Rural Extension and perform more specific searches.
\end{abstract}

Keywords: Occupational hazards; Agricultural activities; Rural worker; Profile and Rural Extension. 


\section{INTRODUÇÃO}

Entende-se por acidente do trabalho aquele que envolve o ferimento humano e a súbita interrupção da ação do trabalhador (DWYER, 1989). Embora qualquer trabalhador no exercício de sua profissão esteja sujeito à ocorrência desses acidentes, sem dúvidas a profissão rural encontra-se entre aquelas que apresentam as maiores probabilidades (TEIXEIRA; FREITAS, 2003).

De acordo com Silveira et al. (2005), os trabalhadores rurais realizam atividades arriscadas e insalubres em ambientes propiciadores de diversos riscos ocupacionais, principalmente físicos, químicos, mecânicos, biológicos, ergonômicos e psicossociais (TEIXEIRA; FREITAS, 2003; SILVEIRA et al., 2005; ROBAZZI et al., 2006). Esses riscos propiciam a ocorrência de três situações distintas: acidentes do trabalho típicos - que ocorrem no interior do ambiente de trabalho; acidentes de trajeto - que acontecem no percurso da moradia ao trabalho; e doenças ocupacionais - decorrentes das atividades exercidas no trabalho, bem como a exposição a um ambiente que cause algum dano à saúde do trabalhador (KIRCHHOF et al., 2003).

Ao analisar a evolução do trabalho no meio rural brasileiro, é possível perceber que os riscos ocupacionais sempre existiram, contudo foram intensificados e agravados a partir da década de 1940 em função das inúmeras e profundas transformações que afetaram o ambiente do trabalho rural, provocando o aumento da ocorrência de acidentes. A política de modernização da agricultura, edificada sobre a difusão de tecnologias, aproximou o trabalho rural do modelo de produção taylorista/fordista, com sua crescente fragmentação de tarefas e rotinização, bem como externalização de riscos. Isso desencadeou, à modelo do que vinha ocorrendo no trabalho urbano industrial, um processo de precarização das condições de trabalho e de desproteção social do trabalhador rural, com consequências diretas sobre sua saúde (GOMEZ; THEDIM-COSTA, 1999).

Embora muito tempo tenha se passado desde o período da modernização da agricultura e mudanças tenham sido instituídas, ainda nos dias atuais os acidentes do trabalho no meio rural representam um problema social de relevância, que é agravado em virtude das subnotificações e da escassez de informações, as quais tendem a menosprezá-lo.

Conforme Silva et al. (2001), o Brasil é campeão mundial em subnotificações de acidentes do trabalho, o que torna a tarefa de quantificar com exatidão a ocorrência de acidentes no trabalho rural difícil, senão impossível. Além do problema de subnotificação, é importante frisar que existe uma carência de informações a respeito de acidentes do trabalho no geral, já que a literatura científica que trata a respeito do tema é bastante limitada. Quando se trata de acidentes do trabalho no meio rural, a situação é ainda mais crítica, tendo em vista a incompatibilidade entre a precariedade das pesquisas e a importância assumida pela temática.

Diante do exposto, a partir do entendimento de trabalhador rural como pessoa física, natural ou jurídica, que explora a terra visando à produção vegetal, criação de animais e também a industrialização desses produtos primários como a produção agroindustrial (STÉDILE, 2005), o presente estudo teve por objetivo analisar os acidentes do trabalho rural do tipo típicos vinculados ao Hospital Universitário de Santa Maria (HUSM), RS, Brasil, entre os anos de 2010 e 2012. De forma específica, buscou-se delinear o perfil dos trabalhadores rurais acidentados e caracterizar os acidentes ocorridos, bem como realizar algumas breves ponderações a respeito da intervenção da Extensão Rural frente a este problema social.

\section{METODOLOGIA}

\subsection{Localização espaço-temporal da pesquisa}

O estudo foi desenvolvido no Hospital Universitário de Santa Maria (HUSM), localizado no município de Santa Maria, RS, Brasil. Órgão público vinculado à Universidade Federal de Santa Maria (UFSM), o HUSM é considerado referência para a $4^{a}$ Coordenadoria Regional de Saúde, que equivale à mesorregião Centro Ocidental Rio-Grandense, formada por três microrregiões e trinta e dois municípios. Dessa maneira, a atuação do HUSM abrange uma área de $25.954,7 \mathrm{~km}^{2}$ e uma população de 536.938 pessoas, sendo que dessas $19,1 \%$ vivem no rural (FEE DADOS, 2010). 


\subsection{Delineamento de pesquisa e fontes de coleta de dados}

O delineamento utilizado foi o de pesquisa documental, definido por Gil (2011) como aquele que utiliza dados obtidos de maneira indireta (dados secundários), oriundos de materiais que não sofreram tratamento analítico ou que podem ser reelaborados de acordo com os objetivos da pesquisa, evitando perdas de tempo e constrangimentos intrínsecos da coleta de dados diretamente com pessoas.

As fontes documentais empregadas foram as Fichas Individuais de Notificação (FIN's) do Sistema de Informação de Agravos de Notificação (SINAN), através das quais as unidades de saúde de todo o território nacional registram a ocorrência de problemas de saúde de forma padronizada, permitindo o posterior processamento de tais dados e a caracterização tanto do paciente, quanto do problema de saúde.

\subsection{Plano amostral}

O universo de análise do estudo foi constituído de forma não probabilística intencional através da tipologia de amostra por caso único de meio institucional (POUPART et al., 2010), aqui representado pelo Hospital Universitário de Santa Maria (HUSM). Utilizado como unidade de acesso aos elementos da população, o HUSM foi selecionado por ser referência em saúde para a região Centro Ocidental do Estado e por apresentar conveniência à entrada dos pesquisadores, em função do vínculo em comum com a Universidade Federal de Santa Maria (UFSM).

Dentro do meio institucional constituído pelo HUSM, a amostra foi efetivamente formada a partir do acesso à população de registros do Sistema de Informação de Agravos de Notificação (SINAN), após as devidas autorizações da administração do hospital e da aprovação e registro do estudo no Comitê de Ética e Pesquisa1.

É importante frisar que a amostragem foi realizada de forma não probabilística em função da necessidade de adequação entre o tipo de amostra e o objeto da pesquisa e dos atributos definidos como essenciais na intersecção do conjunto de características gerais dos componentes amostrais (POUPART et al., 2010; FONTANELLA et al., 2008). Assim, tendo em vista que o estudo é voltado a acidentes do trabalho rural, alguns recortes amostrais se fizeram necessários. Dessa forma, as Fichas Individuais de Notificação (FIN's) foram selecionadas conforme quatro critérios de inclusão: 1) agravo/doença do tipo "acidente de trabalho grave"; 2) tipo de acidente "típico"; 3) ocupações de acidentados vinculadas ao trabalho no meio rural, como "produtor agrícola polivalente", "trabalhador volante da agricultura", "produtor agropecuário em geral", etc. 4) e ocorrência nos anos de 2010, 2011 e 2012.

Dessa maneira, a amostra de estudo foi numericamente equivalente à quantidade de casos de trabalhadores rurais atendidos no HUSM nos anos de 2010, 2011 e 2012 em função de acidentes do trabalho típicos, totalizando uma amostra de 38 casos $(n=38)$.

$\mathrm{O}$ plano amostral da pesquisa pode ser visualizado sinteticamente na Figura 01.

Amostragem nåo-probabilistica intencional

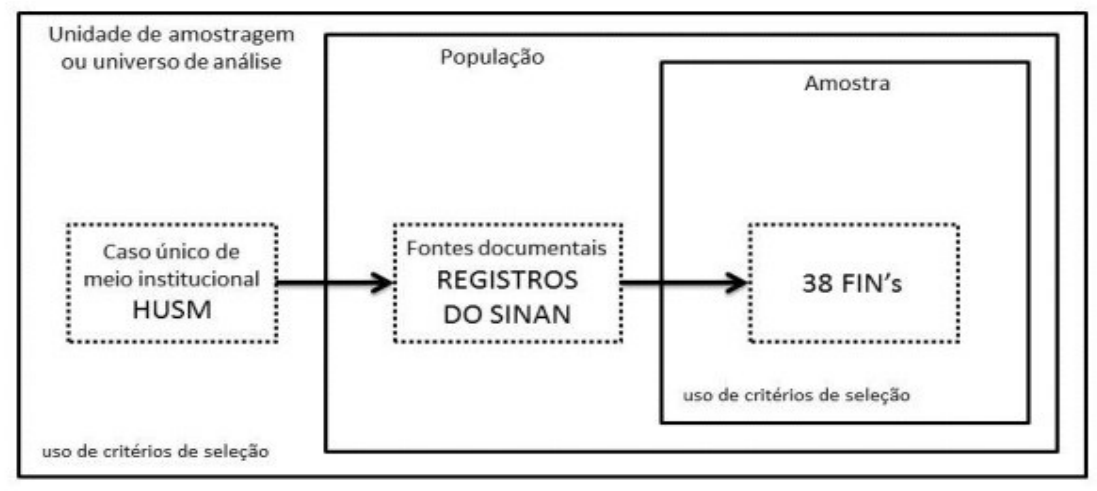

Acidentes do trabalho rural

Figura 01 - Esquema ilustrativo do plano amostral da pesquisa.

Fonte: elaborado pelas autoras.

1 Pesquisa registrada e aprovada na Plataforma Brasil sobre o número CAAE 27578914.3.0000.5346. 


\subsection{Análise dos dados}

Os dados obtidos foram analisados com auxílio do software Statistical Package for the Social Sciences (versão IBM SPSS Statistics 22), recurso referencial na análise estatística de dados em ciências sociais (BRUNI, 2009). Para isso, foi organizado um banco de dados no SPSS contemplando as dezessete variáveis extraídas dos documentos analisados, as quais oscilaram entre variáveis quantitativas contínuas e discretas e variáveis qualitativas ordinais e nominais.

Tendo em vista a predominância de variáveis qualitativas e a não ocorrência de correlações significativas entre as variáveis quantitativas, a análise dos dados envolveu, sobretudo, descritivos, frequências, tabelas de referência cruzada e comparação de médias, com o apoio de gráficos, tabelas e ilustrações para a expressão dos resultados. Além disso, a análise foi enriquecida por meio da busca de fontes bibliográficas afins, capazes de auxiliar na interpretação.

\section{RESULTADOS E DISCUSSÃO}

\subsection{Perfil sociodemográfico e profissional dos trabalhadores rurais acidentados}

Com base na amostra estudada $(n=38)$, buscou-se, primeiramente, traçar o perfil dos trabalhadores rurais acidentados atendidos no Hospital Universitário de Santa Maria (HUSM), entre os anos de 2010 e 2012. Para isso, foram exploradas as informações fornecidas pelas variáveis constantes nos registros do Sistema de Informação de Agravos de Notificação (SINAN), as quais puderam ser vinculadas a aspectos sociodemográficos (idade, gênero, grau de escolaridade e raça/cor) e aspectos profissionais (tempo de profissão em anos, zona de residência e situação no mercado de trabalho). Estas variáveis foram analisadas isoladamente através de descritivos e frequências e algumas foram analisadas em relação a outras, através de tabelas de referência cruzada e comparação de médias.

As idades mínima e máxima apresentadas pelos trabalhadores rurais acidentados de forma típica foram de 24 e 71 anos, respectivamente, com média de 45,7 anos $(\square=12,3)$. A maior parte dos acidentes aconteceu com trabalhadores rurais com idades situadas no intervalo etário de 31 a 60 anos (78,9\%), como é possível visualizar na Tabela 01. Esse resultado diverge tanto de Jesus e Brito (2009), quanto de Teixeira e Freitas (2003), os quais apontam maiores incidências de acidentes com trabalhadores rurais jovens de 15 a 24 anos e 20 a 24 anos, respectivamente. Contudo, as idades dos acidentados do trabalho rural atrelados ao HUSM convergem com os resultados de Fehlberg et al. (2001) e Silveira et al. (2005), onde os acidentes predominaram nas faixas etárias de 16 a 60 anos e 20 a 50 anos, respectivamente. Uma explicação plausível para o resultado encontrado é o conservadorismo dos trabalhadores rurais mais velhos, que não apresentam a característica de atualização das práticas trabalhistas, tornando-se mais vulneráveis aos riscos ocupacionais e a consequente ocorrência de acidentes.

Conforme a Tabela 01, houve uma prevalência majoritária de acidentes do trabalho rural típicos com trabalhadores do sexo masculino (94,7\%). Isso pode ser explicado em função de uma característica bastante tradicional no trabalho do meio rural, que consiste na sua divisão por sexo, a qual atribui ao homem a esfera da produção e à mulher a esfera da reprodução. Assim, o homem é responsável pelas atividades produtivas geradoras de renda, enquanto a mulher fica a encargo de atividades domésticas e auxiliares. Entre ambos os tipos de atividades, os riscos ocupacionais são mais contundentes na esfera de trabalho masculina, o que justifica o resultado encontrado no presente estudo, bem como os resultados similares encontrados por Silveira et al. (2005), Teixeira e Freitas (2003) e Fehlberg et al. (2001).

Quanto à raça ou cor da pele (Tabela 01), verificou-se uma expressividade maior de ocorrência de acidentes típicos entre trabalhadores rurais brancos $(97,4 \%)$. Esse resultado difere do apresentado por Fehlberg et al. (2001) e refuta a hipótese levantada por estes de que a cor seria um indicativo de condições desfavoráveis de vida e trabalho e, consequentemente, de riscos ocupacionais. O alto percentual de brancos acidentados também pode ser explicado pelas características de colonização do espaço territorial de abrangência do HUSM, já que a mesorregião Centro Ocidental Rio-Grandense na qual ele está inserido é marcadamente constituída por muitos municípios de colonização europeia. No que tange a variável grau de escolaridade (Tabela 01), os dados do SINAN mostram que a maior parte dos acidentes do trabalho rural típicos registrados no HUSM, entre 2010 e 2012, ocorreu com trabalhadores dotados de baixo nível de instrução. Entre os acidentados, não houve nenhum registro de Ensino Superior e apenas um de Ensino Médio completo, máximo nível escolar encontrado na 
Tabela 01 - Distribuição dos acidentados típicos do trabalho rural atendidos no HUSM em relação às características sociodemográficas: idade, sexo, raça/cor e grau de escolaridade. Santa Maria, RS, Brasil $2010 / 2011 / 2012$.

\begin{tabular}{|c|c|c|}
\hline \multirow{2}{*}{ Variável } & \multicolumn{2}{|c|}{ Frequência } \\
\hline & $\mathrm{Fa}(\mathbf{n})$ & $\operatorname{Fr}(\%)$ \\
\hline \multicolumn{3}{|l|}{ Idade } \\
\hline $20-30$ anos & 4 & 10,5 \\
\hline $31-40$ anos & 11 & 28,9 \\
\hline $41-50$ anos & 7 & 18,4 \\
\hline $51-60$ anos & 12 & 31,6 \\
\hline $61-70$ anos & 3 & 7,9 \\
\hline$>70$ anos & 1 & 2,7 \\
\hline \multicolumn{3}{|l|}{ Gênero } \\
\hline Masculino & 36 & 94,7 \\
\hline Feminino & 2 & 5,3 \\
\hline \multicolumn{3}{|l|}{ Raça/cor } \\
\hline Branca & 37 & 97,4 \\
\hline Negra & 1 & 2,6 \\
\hline \multicolumn{3}{|l|}{ Grau de escolaridade } \\
\hline não informado & 1 & 2,6 \\
\hline $1^{a} a ̀ 4^{a}$ série incompleta do Ensino Fundamental & 8 & 21,1 \\
\hline $4^{a}$ série completa do Ensino Fundamental & 6 & 15,8 \\
\hline $5^{a}$ à $8^{a}$ série incompleta do Ensino Fundamental & 16 & 42,1 \\
\hline Ensino Fundamental completo & 5 & 13,2 \\
\hline Ensino Médio incompleto & 1 & 2,6 \\
\hline Ensino Médio completo & 1 & 2,6 \\
\hline Total & 38 & 100 \\
\hline
\end{tabular}

amostra de estudo. A maior parte dos acidentados se situa nas faixas de escolaridade referentes ao Ensino Fundamental incompleto $(79,0 \%)$, resultado que vai ao encontro daquele obtido pelo estudo de Ambrosi e Maggi (2013), no qual 42,0\% dos entrevistados também apresentavam grau de escolaridade vinculado ao Ensino Fundamental. Esses resultados podem ser explicados em função das atividades rurais estarem muito mais atreladas a saberes e práticas tradicionais, aprendidos informalmente no âmbito da família, do que ao conhecimento formal da escola. Dessa maneira, muitos conhecimentos são passados de geração para geração, e assim o filho aprende com o pai, que por sua vez aprendeu com o avô. Isso leva a perpetuação de saberes e práticas, por vezes, defasados e até inseguros, considerados potenciais geradores de riscos ocupacionais que desprotegem socialmente o trabalhador rural e podem vir a ocasionar acidentes. A amostra em estudo permite inferir que quanto mais velho é o trabalhador rural, menor tende a ser o seu grau de escolaridade, já que as médias de idades para as categorias de grau de escolaridade referentes ao Ensino Fundamental se situaram na faixa etária de 41 a 50 anos, enquanto que as médias para as de Ensino Médio ficaram na faixa dos 21 a 30 anos.

No que se refere ao tempo de exercício da ocupação de trabalhador rural, os dados apresentaram grande variabilidade, indo de 1 a 50 anos, com tempo médio de profissão de 23,6 anos $\square=$ 14,0). Embora a ocorrência dos acidentes do trabalho rural tenda a independer da experiência de 
que $70,3 \%$ dos acidentes registrados ocorreram nas propriedades rurais dos acidentados, enquanto que as demais ocorreram fora das propriedades, sendo $24,3 \%$ em instalações de contratantes e $5,4 \%$ em instalações de terceiros.

Os dados dos registros do Sistema de Informação de Agravos de Notificação (SINAN) mostram uma ocorrência média de 12,7 acidentes típicos do trabalho rural por ano no $\operatorname{HUSM}(\sigma=4,2)$. O maior índice foi encontrado no ano de 2012 (42,1\%), seguido por $2010(36,8 \%)$ e, posteriormente, $2011(21,1 \%)$.

Na Figura 03 é demonstrada a distribuição de frequência relativa média dos acidentes do trabalho rural ao longo dos meses dos anos analisados. Neste gráfico percebe-se que os meses de maior ocorrência de acidentes do trabalho rural e maior homogeneidade dessa ocorrência foram agosto $(18,8 \%)$ e junho $(13,2 \%)$.

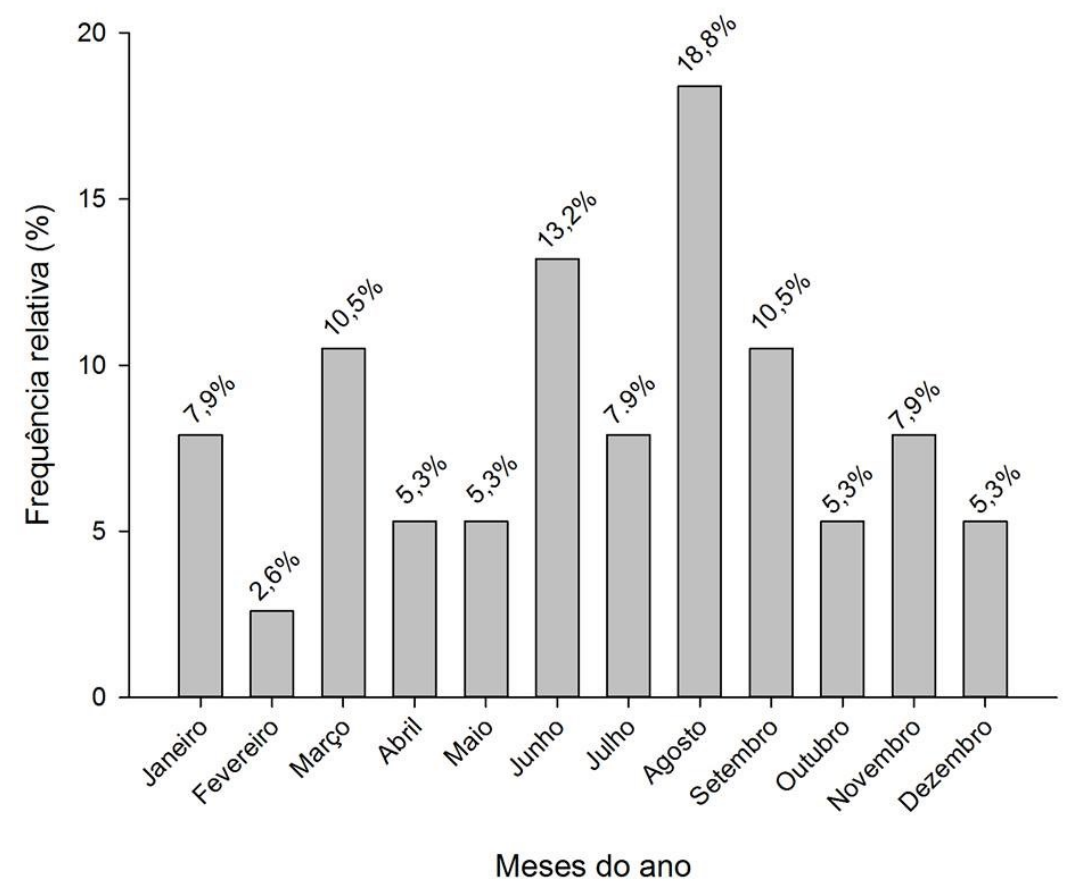

Figura 03 - Distribuição média dos acidentes do trabalho rural típicos vinculados ao HUSM ao longo dos meses dos anos analisados. Santa Maria, RS, Brasil - 2010/2011/2012.

Fonte: elaborado pelas autoras a partir dos dados brutos das FIN's do SINAN obtidas no HUSM.

Com exceção da cultura do trigo, cujo ciclo produtivo abrange os meses de maio a outubro, e da pecuária de corte, que exige manejo constante ao longo de todo ano, constata-se que os meses de maior ocorrência dos acidentes do trabalho rural correspondem ao período da entressafra dos principais cultivos agrícolas da mesorregião, que conforme a FEE Dados (2010) são o arroz, milho, soja, feijão e fumo. Nesse período, é comum o trabalhador rural se dedicar a atividades de manutenção da propriedade, como revisão de maquinário agrícola e conserto de benfeitorias, atividades estas, que também envolvem riscos ocupacionais, tanto quanto as atividades rurais produtivas em si.

É interessante constatar que tais acidentes rurais típicos estiveram relacionados apenas a três tipos de riscos ocupacionais dentre os apontados pela literatura, sendo eles riscos biológicos $(26,3 \%)$, mecânicos (26,3\%) e, principalmente, ergonômicos $(47,4 \%)$.

Através da análise das causas ou agentes causadores de tais acidentes, é nítida a vinculação com as atividades do período de entressafra, como observado na Tabela 02 , sobretudo no que diz respeito a quedas, impacto por objetos e contato com objetos cortantes ou permanentes.

As partes do corpo atingidas nos acidentes do trabalho rural típicos registrados no HUSM entre 2010 e 2012 foram muitas e diversificadas, já que um mesmo acidente de trabalho pode atingir mais de uma parte do corpo do trabalhador. A Figura 04 ilustra que as partes mais atingidas foram os membros inferiores $(42,1 \%)$ e tórax e membros superiores $(13,2 \%)$, ambos ocasionados, sobretudo, por 
Tabela 02 - Distribuição dos acidentes do trabalho rural típicos vinculados ao HUSM conforme a causa ou agente causador. Santa Maria, RS, Brasil - 2010/2011/2012.

\begin{tabular}{lcc}
\hline & \multicolumn{2}{c}{ Frequência } \\
Causa ou agente causador & Fa (n) & Fr (\%) \\
\hline Quedas & 15 & 39,5 \\
Contato com animais & 5 & 13,2 \\
$\begin{array}{l}\text { Contato com máquinas e } \\
\text { implementos }\end{array}$ & 7 & 18,4 \\
$\begin{array}{l}\text { Impacto por objetos } \\
\text { Contato com objetos }\end{array}$ & 2 & 5,3 \\
cortantes ou penetrantes & 5 & 13,2 \\
Outros & 4 & 10,4 \\
\hline \multicolumn{1}{c}{ Total } & $\mathbf{3 8}$ & $\mathbf{1 0 0 , 0}$ \\
\hline
\end{tabular}

Fonte: elaborado pelas autoras a partir dos dados brutos das FIN's do SINAN obtidas no HUSM.

quedas (43,8\% e 80,0\%, respectivamente). No estudo realizado por Fehlberg et al. (2001), os membros inferiores também foram as principais partes do corpo atingidas, com $46,5 \%$ de ocorrência.

No que se refere ao turno, a ocorrência de acidentes típicos se distribuiu de forma equilibrada entre manhã $(44,7 \%)$ e tarde $(50,0 \%)$, sendo que apenas $5,3 \%$ ocorreram a noite. É possível afirmar também, que em média, os acidentes ocorreram 2,8 horas $(\sigma=2,5)$ após o início da jornada de traba1ho. Além disso, cabe destacar que os acidentes mais rápidos foram os vinculados a riscos biológicos, ocorrentes em média 2,0 horas após o início da jornada de trabalho, e os mais demorados vinculados a riscos mecânicos, em média 3,7 horas após o início da jornada, o que permite apontar que estes últimos estão mais relacionados ao cansaço do trabalhador rural do que os demais.

No que se refere à evolução dos casos de acidentes registrados, 17,6\% resultaram em cura, 73,5\% em incapacidade temporária e 8,8\% em incapacidade parcial, não tendo sido registrado nenhum óbito, nem mesmo invalidez permanente. Esses resultados vão ao encontro do estudo de Teixeira e Freitas (2003), no qual a incapacidade temporária também foi a consequência de maior ocorrência (99,7\%). É importante frisar, que os acidentes que evoluíram para as incapacidades foram, principalmente, os vinculados a quedas (40,0\% das quedas ocasionaram incapacidade temporária e $66,7 \%$ ocasionaram incapacidade parcial).

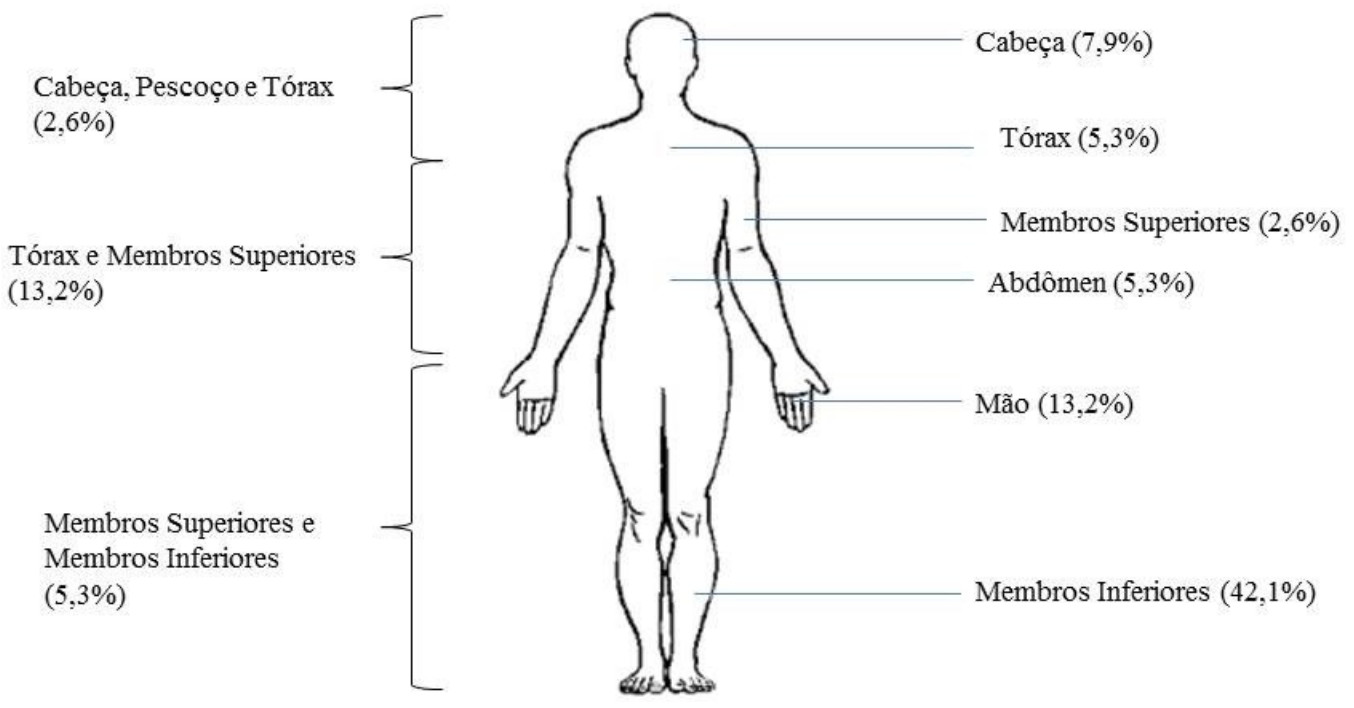

Figura 04 - Distribuição dos acidentes do trabalho rural típicos vinculados ao HUSM conforme as partes do corpo atingidas. Santa Maria, RS, Brasil - 2010/2011/2012.

Fonte: elaborado pelas autoras a partir dos dados brutos das FIN's do SINAN obtidas no HUSM. 


\section{CONCLUSÕES}

O perfil sociodemográfico dos trabalhadores rurais acidentados através de acidentes típicos registrados no Hospital Universitário de Santa Maria (HUSM) entre os anos de 2010 e 2012 é caracterizado por homens brancos e adultos, de baixo nível de instrução formal. Quanto ao perfil profissional, esses trabalhadores são residentes, sobretudo, do meio rural, autônomos e experientes.

Os acidentes típicos do trabalho rural são caracterizados pela variabilidade espacial (ocorrência, sobretudo, na região de abrangência do HUSM, mas em diversos municípios) e pela concentração temporal no período de entressafra. Ocasionados por riscos ocupacionais biológicos, ergonômicos e mecânicos, ao longo de todo o dia, são provocados principalmente por quedas e afetam, sobretudo, membros inferiores e tórax e membros superiores, levando a incapacidade temporária do trabalhador rural.

Os acidentes típicos do trabalho rural vinculados ao HUSM apresentam magnitude suficiente para merecer atenção da Extensão Rural da mesorregião Centro Ocidental Rio-Grandense. Os dados apontam para a necessidade de ações voltadas especificamente ao perfil de trabalhador rural aqui indicado, atentando para o conservadorismo dos trabalhadores rurais mais velhos e experientes, que pode ser considerado um agravante. Além disso, o trabalho de entressafra deve receber atenção especial no que se refere à prevenção de acidentes típicos do trabalho rural. Geralmente negligenciado, ele acaba por multiplicar e agravar os riscos ocupacionais, a desproteção e, consequentemente, os acidentes. Nesse sentido, a Extensão Rural deve trabalhar pela conscientização do trabalhador rural da periculosidade e da necessidade de atenção e proteção em qualquer trabalho realizado, não apenas o produtivo.

Por fim, recomenda-se a realização de estudos sobre acidentes do trabalho rural que coletem dados diretamente dos acidentados, através de questionários ou entrevistas como complemento aos registros documentais dos hospitais, principalmente no que se refere a perfil econômico, perfil produtivo e condições, processos e percepções do trabalhador rural a respeito do seu trabalho. Através disso, será possível esclarecer pontos pouco explorados pelos documentos, entrando efetivamente na especificidade da realidade rural e dos acidentes de trabalho vinculados a ela, gerando maiores subsídios teóricos para balizamento da intervenção da Extensão Rural sobre esse problema social no sentido de prevenção no âmbito da saúde rural.

\section{REFERÊNCIAS}

AMBROSI, J. N.; MAGGI, M. F. Acidentes de trabalho relacionados às atividades agrícolas. Acta Iguazu, Cascavel, v. 2, n. 1, p. 1-13, 2013. Disponível em: $<$ http://e-revista.unioeste.br/index.php/actaiguazu/article/view/7887>. Acesso em: 09 dez. 2013.

BRUNI, A. L. SPSS aplicado à pesquisa acadêmica. São Paulo: Atlas, 2009.

CORREA, I. M.; RAMOS, H. H. Acidentes rurais. Cultivar Máquinas, Pelotas, ano 3, n. 16, p. 24-25, jan./ fev. 2003. Disponível em: <http://www.grupocultivar.com.br/site/content/artigos/artigos.php?id=458>. Acesso em: $10 \mathrm{dez} .2013$.

DWYER, T. Acidentes do trabalho: em busca de uma nova abordagem. Revista de Administração de Empresas, São Paulo, v. 29, n. 2, p. 19 - 31, abr./jun. 1989. Disponível em: <http://rae.fgv.br/sites/rae.fgv.br/files/ artigos/10.1590 S0034-75901989000200003.pdf>. Acesso em: 16 out. 2013.

GIL, A. C. Métodos e técnicas de pesquisa social. 6 ed. São Paulo: Editora Atlas, 2011.

GOMEZ, C. M.; THEDIM-COSTA, S. M. da F. Precarização do trabalho e desproteção social: desafios para a saúde coletiva. Ciência \& Saúde Coletiva, v. 4, n. 2, p. 411-421, 1999. Disponível em: < http://www.scielo. br/scielo.php?script=sci arttext\&pid=S1413-81231999000200015>. Acesso em: 17 out. 2013.

FEHLBERG, M. F.; SANTOS, I. S. dos; TOMASI, E. Acidentes de trabalho na zona rural de Pelotas, Rio 
Grande do Sul, Brasil: um estudo transversal de base populacional. Cadernos de Saúde Pública, Rio de Janeiro, v. 17, n. 6, p. 1375 - 1381, nov./dez. 2001. Disponível em: <http://www.scielo.br/scielo.php?scrip-

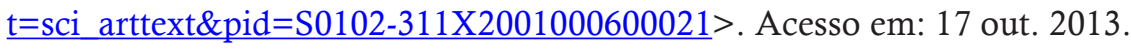

FONTANELLA, B. J. B.; RICAS, J.; TURATO, E. R. Amostragem por saturação em pesquisas qualitativas em saúde: contribuições teóricas. Cadernos de Saúde Pública, Rio de Janeiro, v. 24, n. 1, p. 17-27, 2008. Dis-

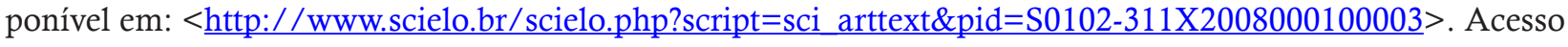
em: 28 nov. 2013.

FUNDAÇÃO DE ECONOMIA E ESTATÍSTICA - FEE. Dados anuais para unidade geográfica Mesorregião Centro Ocidental Rio-Grandense. 2010. Disponível em: <http://www.fee.rs.gov.br/feedados/consulta/ frame consREM.asp?param=Mesorregiao/Centro\%20Ocidental\%20Rio-Grandense/2010>. Acesso em: 04 dez. 2013.

JESUS, C. S. de; BRITO, T. A. Estudo dos acidentes de trabalho no meio rural: análise dos processos e condições de trabalho. Revista Saúde.Com, v. 5, n. 2, p. 141-146, 2009. Disponível em: <http://www.uesb.br/ revista/rsc/v5/v5n2a07.pdf>. Acesso em: 22 out. 2013.

KIRCHHOF, A. L. C. et al. Os acidentes de trabalho atendidos em pronto-atendimento de hospital universitário. Escola Anna Nery Revista de Enfermagem, v. 7, n. 3, p. 361 - 368, 2003. Disponível em: < http://www. redalyc.org/articulo.oa?id=127718223008 >. Acesso em: 17 out. 2013.

POUPART, J. et al. (org). A pesquisa qualitativa: enfoques epistemológicos e metodológicos. Tradução de Ana Cristina Nasser. 2 ed. Petrópolis: Editora Vozes, 2010.

ROBAZZI, M. L. do C. C. et al. Acidentes de trabalho identificados em prontuários hospitalares. Ciência, cuidado e saúde, v. 5, n. 3, p. 289 - 298, set./dez. 2006. Disponível em: <http://www.periodicos.uem.br/ojs/ index.php/CiencCuidSaude/article/.../3251>. Acesso em: 17 out. 2013.

SILVA, J. R. et al. Acidentes graves no trabalho rural entre 1994 e 1997 na região centro-sul do estado de São Paulo, Brasil. Revista Instituto Florestal, São Paulo, v. 13, n.1, p. 83-97, 2001. Disponível em: <http://www. iflorestal.sp.gov.br/publicacoes/revista if/RIF13-1/p.83-97.pdf/>. Acesso em: 17 jan. 2014.

SILVEIRA, C. A.; ROBAZZI, M. L. do C. C.; MARZIALE, M. H. P.; DALRI, M.C. B. Acidente de trabalho entre trabalhadores rurais e da agropecuária identificados através de registros hospitalares. Ciência, cuidado e saúde, v. 4, n. 2, p. 120 - 128, maio/ago. 2005. Disponível em: <http://www.periodicos.uem.br/ojs/index. php/CiencCuidSaude/article/.../5221>. Acesso em: 17 out. 2013.

STÉDILE, S. Agricultura de grupo em Santa Catarina: o caso específico de Condomínios e Associações Leiteiras no Oeste. 2005. 111f. Dissertação (Mestrado em Agroecossistemas) - Universidade Federal de Santa Catarina, Florianópolis, 2005. Disponível em: $<$ http://www.pgagr.cca.ufsc.br/arquivos\%20PGA/dissertacoes/diss2005/stedile sergio.pdf>. Acesso em: $12 \mathrm{dez} .2013$.

TEIXEIRA, M. L. P.; FREITAS, R. M. V. de. Acidentes do trabalho rural no interior paulista. São Paulo em Perspectiva, v. 17, n. 2, p. 81-90, 2003. Disponível em: $<$ http://www.scielo.br/pdf/spp/v17n2/a09v17n2. pdf>. Acesso em: 17 out. 2013. 